\title{
EROTISMO EN LA POESÍA DE MAGALY ALABAU
}

\author{
POR \\ Elena M. Martinez \\ Baruch College (CUNY)
}

El propósito de este trabajo es examinar la representación textual del erotismo lésbico en los poemarios Electra/Clitemnestra (1986) y Hermana (1989) de Magaly Alabau. ${ }^{2}$ Ambos libros presentan un discurso erótico lésbico pero de expresiones diversas. La violencia del discurso erótico de Electra/Clitemnestra se transforma en Hermana en una expresión más tranquila y más sutil.

Electra/Clitemnestra explora la relación de amor y odio entre Electra y su madre Clitemnestra. Libro de diecinueve poemas de gran carga erótica, Electra/Clitemnestra se distingue por su carácter dramático y narrativo. En este libro, Alabau reelabora el mito de Electra, hija de Agamenón y Clitemnestra. El padre de Electra, Agamenón, se fue a la guerra y su madre, Clitemnestra tiene una relación con Egisto. Sin embargo, si en la versión clásica Electra ayuda a Orestes a vengar la muerte del padre matando a Clitemnestra y a Egisto, aquí Electra mata a su madre, por sentirse rechazada por ella, primero en favor de Medusa y luego de Egisto. Diferente a la versión clásica en que Electra defiende los valores de la familia patriarcal, en el texto de Alabau Electra actúa guiada por el deseo erótico hacia su madre. Así, Alabau deconstruye el mito clásico, leído desde una perspectiva heterosexista como ejemplo del deseo de la hija por el padre, y lo articula desde una óptica lesbiana, subrayando el carácter sexual y la intensidad emocional de las relaciones entre mujeres.

Electra/Clitemnestra supone una re-lectura de los mitos clásicos. En los poemarios de Alabau los relatos mitológicos protagonizados por figuras femeninas tienen un papel central. En su interpretación de los mitos, la poeta intenta una nueva lectura que transforma la tradición. El interés de Alabau en la mitología es parte de una estrategia muy frecuente entre escritoras latinoamericanas de las décadas del setenta y del ochenta de re-escribir la tradición que ha sido silenciada y ocultada y que ha perpetuado los mitos en torno a la mujer como un ser pasivo. Aquí, las mujeres que en los mitos clásicos se representaban como

\footnotetext{
${ }^{1}$ Hago constar mi agradecimiento al PSC-CUNY Grants por el apoyo económico para completar éste y otros proyectos durante el año 1997-1998.

${ }_{2}^{2}$ Autora de varios libros de poesía, entre ellos Electra/Clitemnestra (1986), La extremaunción diaria (1986), Hermana (1989), Hemos llegado a Ilión (1991) y Liebe (1993), Magaly Alabau (Cuba 1945) ha recibido el primer premio del concurso de poesía de la revista Lyra (1988); en el 1992 Hermana recibió el premio al mejor libro en lengua española ortorgado por el Instituto de Escritores Latinoamericanos. En 1990 se le otorgó la beca Cintas.
} 
defensoras de la familia patriarcal, aparecen actuando por su propio bienestar y deseo. Las acciones de las mujeres no están prescritas por la tradición, al contrario, rompen con los cánones de conducta establecidos para las mujeres.

En el poemario de Alabau el mito de Electra se une a otro mito: el de Medusa, personaje enaltecido por feministas como Hélène Cixous como símbolo de orgullo y fuerza femeninos. En el mito clásico Medusa es una de las Gorgonas. Su abundante y rizada cabellera de serpientes petrifica a todos los que la miran e inspira terror a los mortales. Alabau toma el personaje mítico de Medusa, relacionado con castigo, orgullo y competenciay la transforma en la amante de Clitemnestra.

El epígrafe del libro, tomado del Fedro, conecta la falta de correspondencia entre la lectura de Alabau y el mito original: "Falsa es esta historia: nunca anduviste en barco por el mar/ni viste las torres de Troya". La referencia al Fedro subraya dos temas importantes del libro: el tema del amor y el de la violencia. Si el Fedro presenta el tema del amor entre varones, Electra/Clitemnestra presenta el tema del amor desde la visión de las mujeres que lo protagonizan. Aparece en el epígrafe también cierta violencia porque la idea de que la historia es falsa sugiere una manipulación retórica de Alabau. Su lectura implica un acto de violencia ya que los significados han sido alterados y desafiados. El discurso erótico de Electra/Clitemnestra no sólo está fundado en acciones violentas sino también en una violencia verbal en que el erotismo se conecta con un regreso a una libertad primitiva y a un tiempo mítico.

El discurso poético de Electra/Clitemnestra articula diversas perspectivas del erotismo y afirma la violencia y la superioridad de la sexualidad femenina. Los poemas VII y XIX de este poemario tienen interés especial y están marcados por la violencia, compartiendo así la visión del erotismo presentada por Georges Bataille en Erotism: Death and Sensuality y por Monique Wittig en The Lesbian Body. Sin embargo, el discurso erótico de Alabau, como el de Wittig, supone una lectura diferente a la de Bataille, ya que examina el erotismo y la violencia desde una óptica lésbica. Mientras que Wittig presenta ruptura y violencia a niveles lingüístico y cultural e innova en el uso de los pronombres personales combinando el "yo" y el "tú", Alabau innova al explorar la relación sexual de madre e hija.

El poema VII, el más extenso del libro, tiene sesenta y siete líneas y una estructura narrativa. Dividido en cinco momentos dramáticos, el poema describe el acercamiento y el encuentro sexual de Medusa y Clitemnestra. El final del poema, sin embargo, mantiene la ambigüedad acerca de si ha sido Electra la que ha tenido la relación sexual con Clitemnestra o si, por el contrario, se ha limitado a observar la relación sexual entre Medusa y su madre. En el primer momento, la hablante describe los efectos de Medusa en la naturaleza; en el segundo momento describe a Medusa; en el tercero, el acercamiento de Medusa y Clitemnestra; en el cuarto, el acto erótico de las protagonistas, y en el quinto, la acción de Clitemnestra de ver a Electra. Medusa, junto a Electra y a Clitemnestra, es parte de un triángulo lésbico que permite la unión de la maternidad y la sexualidad. Medusa viene a encarnar el papel de la tentadora y destructora, mientras que Clitemnestra encarna a la madre.

La violencia del erotismo en este libro se trabaja a partir de la representación de las mujeres y de sus acciones. Por ejemplo, Medusa se presenta como un animal feroz que seduce a Clitemnestra. La hablante compara a Medusa con una pantera que tiene lomo, 
cresta y pezuñas. El acto sexual de Medusa y Clitemnestra tiene la violencia de la unión de dos fieras:

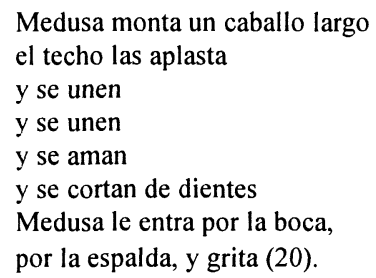

A través de un lenguaje vívido y fuerte, Alabau presenta a Medusa con gran fuerza. Las acciones de las amantes lesbianas son recíprocas como se indica en la repetición de ciertas palabras: "y se unen" "y "se aman" que muestran la igualdad de las amantes. Los verbos que aluden a los encuentros sexuales son precedidos o seguidos por la repetición de verbos que denotan agresión y violencia: "y se unen/y se unen/y se aman/y se cortan de dientes" (20). Todas las imágenes que se usan en este poema para presentar el encuentro sexual denotan gran pasión e indican la furia de las protagonistas:

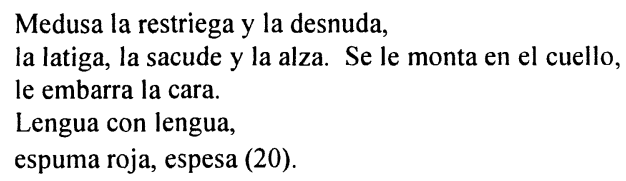

En este poema, la hablante se enfoca en el poder del encuentro sexual. Los símbolos tradicionales fálicos, como serpientes, troncos y cuernos, reaparecen en el contexto de una relación lésbica. El acto sexual entre las protagonistas se ve primero como una lucha y luego como un momento de perfección, unido a un nuevo comienzo: "Dos mujeres vibran, se amoldan/mueren abrazadas/y ya no hay heridas ni cráteres./Micenas renace" (20).

Debido al aura erótica presente en Electra/Clitemnestra, no sorprende que los sentidos jueguen un papel tan importante. La mirada es de relevancia en ésta y en toda la obra de Alabau. La representación de la mirada, tradicionalmente heterosexual, y el poder de mirar ha sido asociado históricamente con los hombres.

En Electra/Clitemnestra la mirada está adscrita a los personajes femeninos y se transforma en elemento clave del erotismo. Se nos presentan referencias al acto de ver y de ser vista por otra mujer. En el verso final del poema VII, Electra aparece en la posición de observadora, y se enfatiza el poder de su mirada. Además, la última línea ("y ve a Electra") introduce la duda acerca de si fue Electra o Medusa quien estuvo con Clitemnestra. Si entendemos que Electra ha espiado la relación de su madre con Medusa, el acto de espiar de Electra articula la marginalidad, al igual que el aspecto prohibido del deseo incestuoso por su madre.

La violencia y el erotismo se refuerzan en el poema por la síntesis verbal y la economía estilística de las que se vale la poeta. Todos estos recursos convergen en un efecto dramático 
que evoca la violencia. Uno de esos recursos es la metonimia. Por ejemplo, en vez de decir que las lenguas lamen, la hablante dice que las caras lamen. La metonimia desafía las expectativas de lectura, a la vez que realza el discurso poético. En otras ocasiones, la poeta invierte el orden de la metáfora: "Mis cuchillos son dientes" en lugar de "mis dientes son cuchillos" (30).

Lleno de imágenes de violencia y muerte, el discurso erótico presenta un conflicto entre la mente y el cuerpo; la mente está asociada a lo racional; el cuerpo a los impulsos y la violencia irracional. El poema textualiza la tensión entre cuerpo y mente y como ésta, trata de controlar y detener la violencia que emerge por la transgresión de una prohibición cultural.

La violencia está también presente en la representación del cuerpo, parte importante del discurso erótico en Electra/Clitemnestra y en The Lesbian Body de Monique Wittig. ${ }^{3}$ En el libro de Alabau, como en el de Wittig, el cuerpo lesbiano aparece como un todo fragmentado y es el lugar de la violencia o es capaz de inflingir violencia. En la representación del cuerpo, las imágenes o las metáforas asociadas con los líquidos son esenciales, pues reiteran el erotismo del texto. Las alusiones a la sangre, el sudor, el vino, la leche, la saliva y las lágrimas son parte del discurso erótico. Las hablantes de Alabau y Wittig prestan atención especial a la cara, los ojos, los oídos, el cuello, la cabeza, las manos, el pecho, la boca, los dedos, los dientes, las pupilas, los orificios del cuerpo y la saliva. Se menciona constantemente el pecho, la leche y la sangre. La fragmentación de los cuerpos es resultado de la violencia de los otros o de las acciones violentas dirigidas hacia ellas mismas. El énfasis en el dolor de las protagonistas en Electra/Clitemnestra indica una relación entre violencia y erotismo, y el interés particular en la representación del cuerpo femenino. La fragmentación del cuerpo articula la intensidad del discurso erótico.

Una de las innovaciones del discurso erótico de Alabau es la presentación del clítoris. Si las perspectivas tradicionales le han negado a la mujer el acceso al placer con la excusa de que carece de pene, en Electra/Clitemnestra, la poeta privilegia el clítoris como el órgano sexual más importante. La presentación del clítoris como zona erótica confronta y subvierte la noción que se centra en el pene con la que se ha excluído a las mujeres del acceso al placer sexual. Liberadas del discurso patriarcal que ha ignorado la sexualidad de las mujeres, las protagonistas de Alabau experimentan una variedad de placeres sexuales.

En este poema Alabau presenta una conexión poco frecuente entre maternidad y deseo. Las alusiones a la leche (tradicionalmente asociadas a la maternidad o como metáfora para el semen), se usan aquí en un contexto estrictamente lésbico-erótico. En el poema VII, los pezones, tradicionalmente asociados a la maternidad, se ven en un contexto de placer sexual -los pechos y los pezones están erotizados y enaltecidos: "Sus pezones se hacen fuentes./ El placer entra" (20). En Electra/Clitemnestra, la representación del cuerpo de la madre, tradicionalmente desexualizada por la necesidad de los hombres de controlarla, aparece como protagonista del amor erótico tanto lésbico (en tanto amante de Electra y/o Medusa) como heterosexual (en tanto amante de Egisto).

\footnotetext{
${ }^{3}$ En otras obras de Alabau, como La extremaunción diaria (1986) y Ras (1987), la violencia tiene otras manifestaciones y no está estrictamente relacionada con el erotismo, sino con la experiencia del exilio o de una condición de desamparo existencial.
} 
La relación madre-hija, relación que no ha recibido suficiente atención en la literatura, el arte y el psicoanálisis, como advierte Adrienne Rich en su libro Of Woman Born: Motherhood as Experience and Institution, adquiere importancia clave en este poemario. A diferencia de los discursos patriarcales basados en la noción de compulsión heterosexual, Alabau explora las relaciones madre-hija desde la óptica del deseo erótico.

En la díada madre-hija la cuestión de la identidad es central. En Electra/Clitemnestra la identidad de Electra se define de forma negativa y como separación de la madre. La competencia entre la madre y la hija prevalece, pero es interesante observar que el deseo sexual tiene un papel clave, como se textualiza en el poema XIV:

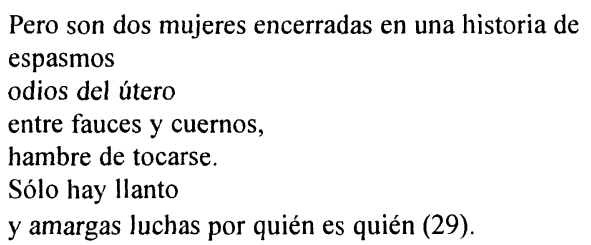

En este poema la rivalidad entre las dos mujeres se presenta por la yuxtaposición de dos líneas:

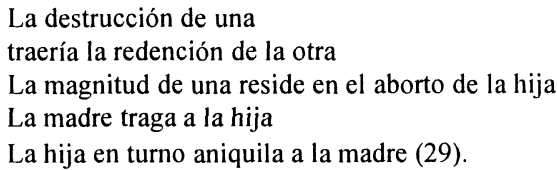

La representación de la relación madre-hija sigue el paradigma freudiano en que la identidad de la hija depende de la separación de la madre, mientras que ambas luchan por el poder y la reafirmación de su propia identidad. Sin embargo, la lectura de Alabau se separa de la interpretación tradicional ya que madre e hija se unen por el deseo sexual.

A diferencia del poema VII, en el que se da una unión sexual violenta, en el poema XIX, el erotismo adquiere otra expresión. La hablante expresa la agresión física de Electra a su madre Clitemnestra hasta darle muerte. El acto de agresión de dar muerte y devorar el útero de la madre es un acto erótico en que, paradójicamente, Electra llega a poseer a la madre. El poema XIX explora los sentimientos de furia y celos de Electra quien - llevada por los celos, pues Clitemnestra tiene un amante en palacio - mata a su madre, no para reestablecer el orden familiar, sino como venganza contra la mujer que no le corresponde sus sentimientos. El matricidio tiene lugar por la intensidad del deseo de la hija por la madre. Con este crimen, la hija valida su deseo erótico y establece un nuevo orden.

El deseo sexual de Electra se origina en el tabú del incesto y está permeado por la violencia, el miedo y la furia. Así, la violencia física se convierte en actividad sexual. El discurso poético presenta el deseo de transgredir el tabú que emerge como respuesta a la violencia del deseo de Electra por su madre. La violencia de Electra tiene que ver con la necesidad de expresar su amor por su madre y a la vez es expresión de la frustración de su deseo. 
El erotismo en este poema recuerda la teoría de Bataille. Aunque la teoría de Bataille sobre erotismo es heterosexual y masculinista hay semejanzas entre los planteamientos del crítico francés y la representación del erotismo en la obra de Alabau. Bataille enumera tres tipos de erotismo: el físico, el emocional, y el religioso. Define el erotismo como la actividad sexual humana que difiere de la actividad sexual de los animales; para él, la actividad sexual se vuelve erótica cuando no es rudimentaria y puramente animal. Para Bataille, el erotismo implica un contraste con lo rutinario y supone siempre una ruptura con lo establecido: "Eroticism always entails a breaking of established patterns, the patterns, I repeat, of the regulated social order basic to our discontinuous mode of existence as defined and separate individuals" (18). Según Bataille, la vida está asociada a la discontinuidad, mientras que la muerte está asociada a la continuidad; el erotismo abre el camino hacia la muerte y, a través de ésta, hacia la continuidad. Es esa tensión entre conciencia y pérdida de conciencia que define el erotismo para Bataille y que se manifiesta en el poema de Alabau. El erotismo sustituye los sentimientos humanos individuales de discontinuidad; las protagonistas en la actividad violenta-erótica están imbuidas con sentimientos de continuidad y pasan por una experiencia de transformación.

El erotismo se conecta en este poema con la violencia, la violación de normas, y lo sagrado. Alabau parece expresar que la corriente de violencia es un elemento íntegro de la vida humana y que los tabúes se originan como una forma de reducir la violencia que prevalece. Así, el erotismo implica necesariamente la transgresión de un tabú, esto es: el impulso de ir más allá de las restricciones que los seres humanos se imponen a sí mismos, como estudia Bataille en Erotism. Death and Sensuality. En Alabau, como en Bataille, el tabú y la transgresión están relacionados con la violencia ya que tienen que ver con el establecimiento de una ley y la violación de ésa. Los lectores somos testigos de la ansiedad unida al acto de la transgresión de un tabú. La experiencia interior de Electra exige una sensibilidad a la ansiedad, al deseo, el terror, y el placer y la angustia. El erotismo, la transgresión de un tabú, está aquí relacionado intrínsecamente a una experiencia interior de violencia. En este poema, como en Bataille, el erotismo físico está conectado con la muerte, la violencia y la excitación.

En la violencia de este discurso erótico, Alabau conecta partes del cuerpo centrales al placer sexual con acciones violentas u objetos que connotan violencia. Por ejemplo, las manos de Electra expresan violencia y frustración contra la madre que no le da amor; finalmente, Electra, con sus manos, matará a Clitemnestra. Algunas imágenes de los cuerpos los comparan a objetos, mientras que otras los comparan o equiparan a animales. En otras ocasiones, el discurso erótico de Electra/Clitemnestra subraya las transformaciones de las partes del cuerpo que sufren los efectos de acciones violentas, en particular encuentros sexuales. Por ejemplo, el cuerpo de Clitemnestra cambia debido a la agresión de Electra y luego la madre y la hija se transforman y se desfiguran en el acto.

El poema XIX, culminación de la trayectoria del deseo de la madre y la hija, presenta una reversión de la relación de Electra y Clitemnestra, pues Clitemnestra es devorada por su hija. Electra muerde y come el útero de su madre: 
La hija, como trofeo, arrancó con la mano el útero

a la madre

lo lavó

lo comió, devorando el primer recuerdo de su vida (35).

El intercambio de roles de madre e hija reitera su conexión básica y primaria. A través de este acto, Electra muestra su deseo de poseer a su madre, de aniquilarla y devorarla. La muerte que aparece al final del libro, es la suma del deseo erótico de Electra. Y Alabau conecta el nacer y el morir, mostrando así la simetría de ambos actos. El matar a la madre es expresión de violencia y la transgresión de un tabú así como expresión de erotismo; sugiere un proceso de identificación y apropiación de la madre. La agresión es un claro desplazamiento del deseo de Electra de poseer a su madre.

El discurso poético de Alabau, a diferencia de los discursos patriarcales, elabora distintos aspectos del placer lésbico. Las protagonistas de la obra de Alabau desafían la representación tradicional que ha excluído a las mujeres del goce de su sexualidad. Su poesía reafirma el acceso de las mujeres al placer sexual.

Una línea de erotismo lésbico diferente se presenta en Hermana. Como en Electral Clitemnestra, las relaciones entre mujeres, tradicionalmente soslayadas, ocupan aquí una posición central.

En Hermana, Alabau reelabora el mito de Orfeo, elogiado por el poder de su voz y la armonía de su lira. Al igual que en su primer poemario, en éste, Alabau presenta el mito de Orfeo y Eurídice desde la perspectiva de las mujeres. Como Wittig en El Opoponax, Alabau recrea aquí el mito de Orfeo pero reemplaza una unión heterosexual con una unión lésbica. Orfeo, quien descendió al submundo a rescatar a Eurídice, se transforma en una poeta que desciende a rescatar a su hermana gemela, creando así, una nueva mitología del descenso. Como en El Opoponax, el poemario de Alabau comienza con la invitación que la poeta le hace a su hermana a soñar y a amar.

A través del poema, y debido a su carga erótica, la relación de las hermanas puede entenderse no como una relación biológica sino como una relación de afinidad lésbica. Esta conexión entre las hermanas gemelas (o amantes) desafía la posición tradicional que las mujeres ocupan en la sociedad homofóbica, en que se les niega la oportunidad de establecer vínculos de solidaridad y apoyo entre ellas. A otro nivel, las experiencias de las hermanas gemelas en la poesía de Alabau son símbolos de experiencias claves en la vida de las mujeres. La hermana que salió del país se puede interpretar como una metáfora de una mujer que se distancia del camino que la familia y la sociedad le han trazado; la que se queda es símbolo de aquélla que acepta el papel social impuesto, pero que a pesar de ello continúa ocupando una posición marginal.

En Hermana y en Electra/Clitemnestra, las lectoras son testigo de una vena diferente de erotismo lésbico. Las uniones sexuales violentas de las protagonistas de Electral Clitemnestra desaparecen en Hermana y se articula la unión emocional de las dos hermanas o las amantes. Contrario a lo que sucede en la anterior colección, en que la rivalidad y la violencia son un aspecto central en la vida de las protagonistas, aquí, Alabau exalta la igualdad y la compenetración emocional. Alabau parece seguir la teoría de Adrienne Rich, la cual rechaza la rivalidad entre mujeres, al verla como algo creado por la sociedad que no 
surge de un instinto natural. Para Rich, la conexión afectiva habla de un conocimiento preverbal compartido por dos cuerpos que son semejantes. Alabau parece compartir la idea de Rich que la semejanza física facilita la comunicación. Así, el erotismo lésbico se elabora en Hermana a partir de la premisa hermandad=igualdad=reciprocidad en la que se enfatizan la ternura, la empatía y la confianza en la relación entre mujeres:

Tu mano agarrada a mí en confianza,

tirando de una tela tan rota como tú, más gris, acostémonos en la hierba, suspiremos el momento, prometámonos ser una, que una muera y que la otra no quede sin mitad. Prometámonos sacar raíces en la otra, que del abismo una semilla escape y en la lengua crezca mezclándose con tierra (26).

El discurso erótico del libro explora la posibilidad de intercambio entre el sujeto y el objeto de escritura. La dualidad y el motivo del doble en este poemario reitera que la construcción de la identidad de la hablante no es independiente de la otra mujer. La dualidad enfatiza el carácter erótico y su carácter lésbico. Junto a la dualidad, la reciprocidad y la igualdad de los personajes femeninos se expresa en la mención de los espejos que aparecen al principio del poemario: "tú y yo somos los espejos". Los espejos aluden al motivo de la relación entre dos personas del mismo sexo y la identificación con quien se está en comunión total o parcial. La referencia a los espejos y el aspecto intercambiable de las identidades de las protagonistas presenta la noción de que la otra mujer facilita la reflexión del ser de la hablante y viceversa. Esta idea rechaza la presentación tradicional según la cual las mujeres son reflejos de las vidas de los hombres o espejos en los que ellos pueden mirarse.

El tema erótico-lésbico se textualiza a través de la posibilidad de intercambiar el "yo" y el "tú", así como en la insistencia en la primera persona plural como resultado de la unificación del "yo" con el "tú". Alabau, en la tradición de Wittig, explora el uso de dos pronombres en su obra, articulando la comunión de las identidades lésbicas a través de la fusión de los pronombres "Tú/Yo": "Dos horas tranquilas en un viaje que podría suscitar alegría/pero encontrarme contigo es como ahora tuyotuyotuyo" (20).

Hermana es una celebración y una exploración de la fusión y comunión de dos mujeres. La comunicación entre las dos mujeres se establece desde el principio del libro por medio del epígrafe de Søren Kierkegaard:

Así, cuando aprieto mis labios contra este papel no es mi sello lo que pongo sino el tuyo. Es tuyo pero yo lo guardo. Sabes también que en los anillos del sello las letras están invertidas: por eso la palabra "tuyo" con que tú autentificas y validas la posesión, vista desde mi lado se lee "mía" (i).

Y a través del poemario, la intensidad de las hermanas se textualiza en la cercanía física y la semejanza de los cuerpos de las mujeres: 


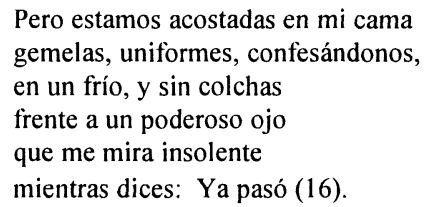

En algunas instancias la cercanía se presenta por medio de la interconexión de los cuerpos de las mujeres. Ellas pasan a formar parte de un solo cuerpo y son una sola entidad: "No puedes extender los brazos/porque los tienes registrando dentro/ de mi espina dorsal" (36). La palabra "dentro" denota la cercanía física y los lazos emocionales de las amantes.

Las partes del cuerpo están en función de la conexión especial entre las dos mujeres, como se presenta por medio de la carga emotiva de la cercanía de las hermanas. Verbos tales como "tocar", "abrazar", "amarrarse" abundan en el libro: "No nos sentaremos en el sillón/ abrazadas, amarradas, donde a toda costa/respiraría en tus orejas música/para quitar el azoro que te circunda" (26). La alusión a los ojos y el término "orgasmo" contribuyen a establecer la calidad erótica que define el libro: "Tú y yo/mirando el techo, con ganas de orinar./Tú, tocándome los ojos./El orgasmo y tu llanto" (32).

Las zonas erógenas de las hermanas gemelas se extienden a todo el cuerpo. La sensualidad no es directa e inmediata sino que la hablante enfatiza una atmósfera de intimidad y ternura que no aparece en Electra/Clitemnestra. Aquí, la culminación, el clima sexual se ve como un momento de perfección. El erotismo lésbico en Hermana es muy sutil, como si Alabau estuviera respondiendo a la homofobia. El vínculo erótico se caracteriza por la comunión de las mujeres y la intimidad que comparten en la cama o cuando bailan abrazadas como "hermanas":

\section{Bailamos y sabes que te daré mis ojos mientras esta canción fluya (48).}

De Electra/Clitemnestra a Hermana el discurso erótico lésbico de la poesía de Magaly Alabau pasa por un proceso de transformación. En ese proceso la representación de las relaciones y del erotismo entre mujeres pasa, de estar atravesado por la violencia y la rivalidad, como vimos en Electra/Clitemnestra, a un erotismo más sutil, basado en sentimientos de ternura. El erotismo presentado en Hermana permite la celebración de la cercanía y la conexión entre mujeres a la vez que reconcilia su vida erótica y emotiva.

\section{BiBLIOGRAFIA}

Alabau, Magaly. Electra/Clitemnestra. Concepción, Chile: Libros del Maitén, 1986. Hermana. Madrid: Betania, 1989.

Bataille, Georges. Erotism, Death and Sensuality. Mary Dalwood, trad. San Francisco: City Lights Books, 1986. 
Benjamin, Jessica. "The Bonds of Love: Rational Violence and Erotic Domination". Feminist Studies 6/1 (Spring, 1980): 144-173.

Cixous, Helene. "The Laugh of the Medusa". Signs. A Journal of Women in Culture and Society 1/4 (Summer, 1976): 875-893.

Rich, Adrienne. OfWoman Born: Motherhood as Experience and Institution. Nueva York: W.W.Norton, 1976.

Wittig, Monique. The Lesbian Body. David Le Vay, trad. Boston: Beacon Press, 1975. "The Straight Mind". Feminist Issues 1/1 (Summer, 1980): 103-112. Les Guérillères. Nueva York: Viking Press, 1971.

y Sande Zeig. Lesbian Peoples: Material for a Dictionary. Nueva York: Avon Press, 1979. 